\title{
Entrevista: Helena Hirata
}

Interview: Helena Hirata

Resumo Socióloga e pesquisadora do GEDISST (Groupe d'Etudes sur la Division Sociale et Sexuelle du Travail) no CNRS (Centre National de la Recherche Scientifique), na França, Helena Hirata tem se dedicado nos últimos anos à análise dos efeitos do processo social de mundialização nos sistemas de produção, na organização do trabalho e nas relações de trabalho. Neste sentido, temas candentes para a sociedade brasileira e a produção acadêmica nacional têm se destacado em sua produção mais recente, a exemplo da investigação sobre a intensificação da vulnerabilidade das relações de trabalho, a polarização entre trabalho produtivo e trabalho improdutivo, as relações entre desemprego e subemprego e a reorganização produtiva e organizacional. Este conjunto de temas, caros à sociologia do trabalho, são revisitados sob a perspectiva dos estudos de gênero e da problematização das relações de gênero. Nesta entrevista, ela discorre sobre a sexualização dos objetos da sociologia do trabalho, as relações de poder, a divisão social de trabalho e as relações de gênero no mundo ocidental, além de tecer considerações acerca do lugar do trabalho na construção da identidade de gênero feminina.
Abstract Helena Hirata is a sociologist and researcher of the Groupe d'Etudes sur la Division Sociale et Sexuelle du Travail at the Centre National de la Recherche Scientifique, in France. In the last few years, she has been devoted to analyzing the social process of globalization in production systems, in the organization of labor and in labor relations. Her latest works approached relevant themes for Brazil and the country's academic work, such as the study of the increase in the vulnerability of labor relations, the divergence between productive and unproductive labor, the relations between unemployment and underemployment and the rearrangements of production and organization. These themes are dear to the sociology of labor and Helena Hirata has revisited them through the viewpoint of gender studies and on the perspective of the discussion of gender relations. In the interview, she speaks of the increasing relevance of gender matters for the sociology of labor, of power relations, of the social division of labor and of gender relations in the western world. She also comments on the influence of the workplace in the development of the identity of the woman. 


\section{Revista}

Gostaríamos de iniciar explorando um pouco as relações entre a sociologia do trabalho e os estudos de gênero. É possível, por exemplo, considerarmos uma perspectiva de gênero para analisar os objetos atuais da sociologia do trabalho? Como repensar a categoria sociológica do trabalho a partir da introdução do conceito de gênero e da problematização da divisão sexual do trabalho?

\section{Helena Hirata}

Tradicionalmente, a sociologia do trabalho francesa teve como objeto central o operário do sexo masculino da grande empresa industrial, figura arquetípica considerada como universal. Essa figura, considerada universal, mas na realidade masculina, vem sendo questionada de trinta anos para cá, com o crescimento do emprego feminino e com o desenvolvimento do terciário (comércio e serviços), setor majoritariamente feminino. As pesquisas sobre divisão sexual do trabalho e relações sociais de sexo/ gênero mostraram que uma análise dentro de uma perspectiva de gênero muda radicalmente as condições de produção dos conhecimentos sobre o trabalho. Assim, os trabalhos masculino e feminino não são comparáveis, sobretudo se partimos do conceito amplo de trabalho, enquanto trabalho formal e informal, profissional e doméstico, remunerado e não-remunerado. A introdução do conceito de gênero nas análises dos objetos tradicionais da sociologia do trabalho, como o emprego, o desemprego, a qualificação, os movimentos sociais, os novos modelos produtivos ou a 'especialização flexível', subverte a ordem epistemológica dominante e produz novos conhecimentos. Qualificação, por exemplo, não tem a mesma significação conjugada no masculino ou no feminino. O desemprego tem implicações contrastadas para homens e mulheres. Os processos de requalificação atingem os homens, e muito pouco as mulheres na produção. Creio que se pode dizer que a introdução do conceito de gênero na sociologia do trabalho renovou os conceitos e os enfoques sociológicos; infelizmente, os paradigmas hoje predominantes na disciplina ainda são gender-blinded e não levam em conta os resultados das pesquisas mencionadas.

\section{Revista}

Seria possível estabelecermos algum tipo de relação entre a vulnerabilidade das relações de trabalho nas últimas décadas e a intensificação do processo de sexualização dos objetos da sociologia do trabalho?

\section{Helena Hirata}

Poderíamos dizer que o emprego feminino é, em todos os países, mais precário e instável que o emprego masculino. A maioria dos empregos de 'tempo parcial' ou de 'meio-período' nos países capitalistas desenvolvidos são ocupados por mulheres, assim como as atividades informais nos países ditos em vias de desenvolvimento. Esses empregos femininos precários podem prefigurar o padrão de assalariamento do futuro para ambos os sexos. Nessa medida, talvez a análise das formas ditas 'atípicas' do trabalho feminino hoje seja pertinente para se pensar a evolução das relações de trabalho para ambos os sexos. Sexualizar os objetos da sociologia do trabalho pode ajudar a melhor compreender a evolução da conjuntura do emprego e das relações profissionais nas últimas décadas.

\section{Revista}

A sociologia do trabalho tradicionalmente se centrou na análise da população ativa, do trabalho profissional e do mercado de trabalho. De muitos modos, esses focos construíram nossa compreensão do trabalho como processo social. Como os estudos de gênero têm contribuído para salientar outras dimensões do trabalho, particularmente no tocante à polarização entre trabalho produtivo e trabalho improdutivo?

\section{Helena Hirata}

Os estudos de gênero têm, sobretudo, contribuído para ampliar o conceito de trabalho para além do trabalho profissional, restituindo a importância devida ao trabalho doméstico e ao trabalho exercido pelas mulheres no interior da família. A gratuidade dessa modalidade de trabalho repercute sobre o trabalho profissional das mulheres, que é constantemente desvalorizado e não reconhecido. Penso que o debate marxista sobre trabalho produtivo e improdutivo, que dominou a polêmica sobre o trabalho doméstico nos anos setenta e oitenta, foi suplantado pelo estudo empírico das característi- 
cas constitutivas do trabalho doméstico, como relação de 'disponibilidade permanente' aos filhos, ao marido, ao companheiro, etc. Essas análises apontam hoje para uma outra dimensão do trabalho, a dimensão da afetividade, do amor, que está no cerne do exercício do care no interior da família. A dificuldade em lutar contra a divisão sexual do trabalho doméstico, que aloca à mulher as tarefas relacionadas à casa e às crianças, liberando o homem para as responsabilidades na esfera profissional, está nessa dimensão de afetividade, que cria uma relação de 'servidão voluntária' das mulheres.

\section{Revista}

Partindo de suas experiências (empíricas) de pesquisa em países do norte e do sul, é possível identificar diferenças no modo como a produção sociológica local incorpora as relações sociais de gênero na problematização do trabalho?

\section{Helena Hirata}

Uma diferença é o momento, segundo os países, da introdução do conceito de gênero ou de sexo(s), que sempre se sucede ao enfoque a partir do conceito de 'mulher(es)'. O momento da incorporação das relações sociais de gênero na problematização do trabalho também varia segundo os países. No conjunto dos países latino-americanos, a década das mulheres, impulsionada pela Organização das Nações Unidas no México, em 1975, pode ser um marco para essa periodização, pois assinala o início da constituição de uma série de grupos feministas. Nos países capitalistas avançados, a emergência dessas pesquisas pode ser relacionada com o desenvolvimento dos movimentos feministas nos anos sessenta e setenta. Outra característica a mencionar é a quase total impermeabilidade dos sociólogos do trabalho às pesquisas sobre o gênero da filosofia queer ou à psicanálise feminista. As diferenças nacionais aparecem, sobretudo, nas influências disciplinares: a psicopatologia e a psicodinâmica do trabalho na França, a sociologia da cultura e a gestão nos países anglo-saxões. Em termos temáticos, enfim, também se pode identificar diferenças no modo como a produção sociológica local incorpora as relações de gênero: a questão da centralidade do trabalho e da diferença dessa centralidade para homens e mulheres aparece quase que exclusivamente na França, e não é um tema recorrente nas sociologias do trabalho de outros países.

\section{Revista}

Os estudos feministas influenciados por Sandra Harding e Donna Haraway, ao problematizarem a construção sócio-sexual da cultura e dos padrões de verdade, podem contribuir na compreensão de algumas dimensões relacionadas à divisão sexual do trabalho, tais como o afastamento das mulheres das posições de poder e do processo de concepção dos modelos produtivos e de seus padrões tecnológicos.

\section{Helena Hirata}

A contribuição das duas filósofas americanas citadas para a constituição de uma epistemologia feminista foi fundamental. Elas interrogaram a natureza da objetividade, o acesso desigual ao conhecimento segundo os sexos, a relação entre sujeito e objeto do conhecimento, a construção social - e sexuada - da natureza, da verdade ou da cultura. Essa tradição anglo-saxã de uma epistemologia feminista, infelizmente, não teve a devida repercussão na França e nos países europeus em geral. A idéia do 'ponto de vista' ou do 'conhecimento situado' coloca mulheres, minorias étnicas ou raciais, etc. no centro da elaboração de uma nova ordem de conhecimento.

\section{Revista}

As últimas décadas foram marcadas pelo processo de interdependência crescente dos mercados locais, com conseqüências para os padrões locais de produção e de consumo. De modo geral, a dinâmica dos mercados de trabalho locais se alterou profundamente, não só elevando o nível da taxa de desemprego, mas também modificando as formas de contratação e a relação entre os mercados formal e informal de trabalho. As mudanças nas formas e modalidades de emprego são uma dimensão visível das transformações do mundo do trabalho sob a reorganização produtiva e organizacional. Nesse sentido, qual o lugar do trabalho na construção da identidade de gênero feminina e masculina neste princípio de século? 


\section{Helena Hirata}

A globalização teve como conseqüência, desde os anos noventa, a elevação dos níveis de emprego das mulheres, mas, ao mesmo tempo, acelerou o processo de vulnerabilidade e precarização desses empregos. A esse paradoxo, responde um segundo, o da dispersão e atomização das mulheres, dadas as mudanças nas modalidades de emprego (trabalho a domicílio, teletrabalho, formas ditas 'atípicas' de emprego, etc.) e a criação, ao mesmo tempo, de coletivos de luta unificadores, como a "Marcha Mundial das Mulheres". O trabalho continua sendo central na vida de mulheres e homens neste princípio de século, mesmo quando eles estão desempregados, dado que continua sendo uma referência para a ação e princípio organizador da sociedade e das identidades sexuais. A crítica do trabalho enquanto atividade imposta, coercitiva, alienante e degradante se impõe hoje, mais do que nunca, dada a extensão mundial desse tipo de trabalho, mas as alternativas possíveis e desejáveis devem ser objeto permanente de debate. Este é o caso na França, especialmente dentro dos movimentos de trabalhadores desempregados, que se recusam a lutar pelo 'pleno emprego' e não querem 'qualquer emprego', mas um emprego interessante, de qualidade.

\section{Revista}

Que políticas sociais poderiam contribuir para a desaceleração da vulnerabilidade do emprego feminino, marcado pela precarização e pela subcontratação?

\section{Helena Hirata}

Um tratamento mais igualitário entre emprego masculino e feminino é o objetivo das políticas preconizadas pela Comunidade Européia, por exemplo, ou pela Organização das Nações Unidas, que têm sido retomadas pelos Estados Nacionais. As políticas de igualdade, de uma maneira geral, e uma política de igualdade salarial, em particular, poderiam contribuir para uma maior equidade no tratamento entre os sexos, sobretudo considerando a maior escolaridade formal e o maior número de diplomas em todos os níveis obtidos pelas mulheres, em comparação com os homens. Também todas as políticas sociais e familiares que possam diminuir o fardo da responsabilidade no tocante às crianças, aos idosos, aos enfermos - que recai fundamentalmente sobre as mulheres -, socializando essas tarefas, poderiam contribuir para uma melhora da situação das mulheres no mercado de trabalho.

\section{Revista}

Quais são, em linhas gerais, as conseqüências, para a força de trabalho feminina, do processo de requalificação que tem acompanhado a adoção do modelo produtivo pós-fordista?

\section{Helena Hirata}

O processo de requalificação não teve as mesmas consequências para homens e mulheres. Para os homens, a profissionalização, as avaliações sobre as competências, os cursos de formação têm sido mais sistemáticos do que para as mulheres. Minhas pesquisas sobre empresas multinacionais no Brasil mostraram que as mulheres continuam ainda muito mais em linhas de montagem e com cadências impostas do que os homens. Elas continuam a trabalhar dentro de um padrão taylorista-fordista de produção, inclusive em países como a França. Esse resultado de pesquisa converge com os dados disponíveis sobre as empresas francesas. A inserção da força de trabalho feminina nos trabalhos repetitivos e monótonos sob cadência tem, como uma das consequências nefastas sobre a saúde, o aumento importante de casos de LER. Em algumas empresas modernas, o padrão pode ser de uma certa requalificação também para as mulheres, mas essa requalificação não significa salários condizentes ou promoções. A segregação dos postos de trabalho continua sendo desfavorável às mulheres. Creio que se pode dizer que a tese da requalificação dos operadores, em voga nos anos noventa na sociologia do trabalho francesa, deve ser contestada se adotamos uma perspectiva de gênero.

\section{Revista}

A percepção social do trabalho em saúde está assentada sob o modelo do médico varão. A partir dele, o trabalho e as relações sociais de trabalho se estruturaram. Em contrapartida, há uma série de profissões e atividades na saúde identificadas socialmente como trabalho feminino, a exemplo da enfermagem. Um pon- 
to recorrente na fala das enfermeiras é o fato de a população considerar apenas o trabalho médico como essencial. As demais formas de trabalho envolvidas no cuidado à saúde são, nesse sentido, invisíveis ou improdutivas. Como podemos analisar essa situação a partir dos estudos de gênero e trabalho? Ela se manifesta em outros setores?

\section{Helena Hirata}

As profissões como enfermeira ou ajudante de enfermagem são caracterizadas como tipicamente femininas pela proximidade com as tarefas tradicionais das mulheres no interior da família, o conjunto de atividades hoje objeto de intensa pesquisa sob a denominação, difícil de traduzir, de care (cuidado com as crianças, os idosos, os enfermos, etc.). Por causa dessa proximidade com atividades executadas gratuitamente no seio da família, essas profissões femininas são desvalorizadas, inversamente à forte valorização da profissão tradicionalmente masculina do médico, sobretudo do cirurgião. Pesquisas que estudaram a feminização da profissão dos médicos e a masculinização da profissão das enfermeiras mostraram, em primeiro lugar, que a feminização implica também maior salarização da profissão (trabalho em dispensários, clínicas e hospitais); em segundo lugar, que segmentos da profissão que permitem prever e controlar os ritmos e horários de trabalho - como dermatologia, pediatria, ginecologia - se feminizam, e que outros - como cardiologia, cirurgia, neurologia - continuam maciçamente masculinos; e, em terceiro lugar, que a masculinização da enfermagem se dá em função do aumento de postos em psiquiatria, onde se requer maior força física e, em função da introdução de novas tecnologias (ressonância magnética, scanner, etc.) nos hospitais, maior conhecimento técnico. A profissão de enfermagem é, assim, de certa forma, valorizada com a entrada de mão-de-obra masculina. Penso que a divisão sexual do trabalho se superpõe à divisão do trabalho entre concepção e execução, entre trabalho manual e trabalho intelectual. O coletivo de trabalho é responsável pelo produto, e não apenas os que exercem o trabalho mais qualificado em termos de qualificação formal, escolaridade, experiência, etc. Entretanto, assim como na medicina, na universidade, na pesquisa, da mesma forma que nas empresas, a idéia da importância desse cole- tivo de trabalho não predomina. O trabalho do pessoal técnico e administrativo, essencial para a pesquisa científica, é tornada invisível, como se apenas o cientista, o professor universitário pudessem chegar a um produto final, sem a cooperação do coletivo de trabalho. A crítica da divisão do trabalho continua sendo uma questão extremamente atual. 
